\title{
LA MATERNIDAD SEGURA, UNO DE LOS OBJETIVOS DELMILENIO: UNA MIRADA DESDE EL IMAGINARIO SOCIAL
}

\section{SAFE MOTHERHOOD, ONE OF THE MILLENNIUM'S OBJECTIVES: A LOOK FROM THE SOCIAL IMAGINARY}

\author{
Carlos Andrés Romero-Ochoa ${ }^{1}$, José Ignacio Berrocal-Moreno², Kelly Del Carmen-Urzola Vertel${ }^{3}$, Teresa De \\ Jesús Carreño-González ${ }^{4}$
}

Recibido para publicación: Abril 5 de 2017 - Aprobado para publicación: Junio 28 de 2017

Los objetivos del milenio son reconocidos como el acuerdo político más grande que se ha dado en toda la historia de la humanidad $(1,2)$. Es en principio una idea muy fácil de concebir, pero demandó titánicos esfuerzos para conseguir poner de acuerdo a los líderes de 189 países en generar esfuerzos conjuntos en 8 aspectos considerados fundamentales para hacer de este mundo un lugar mejor (3). Muchos líderes mundiales coincidieron en que era necesario aunar esfuerzos para lograr objetivos comunes que favorecieran a toda la humanidad. La guerra fría permitió definir un nuevo vínculo entre paz, seguridad y desarrollo orientado a la construcción de la paz (peace building) y a promover la seguridad humana. La lucha contra la pobreza se situó en el centro de las estrategias de prevención de conflictos, de promoción de la paz en situaciones de conflicto, de reconstrucción y desarrollo tras el conflicto armado. Esa visión fue reconocida por Naciones Unidas y por los donantes de ayuda al desarrollo en la Declaración del Milenio de 2000 (4).

Los científicos y conservacionistas emiten conceptosacercadeldeterioroqueelserhumano ha generado al planeta; en busca de satisfacer sus necesidades de poder (económico, político, social etc.). La Cumbre de Johannesburgo nace ya desde el mismo momento de su partida con un doble desafío: en primer lugar, mejorar las condiciones de vida de todo ser humano y, por otro lado, proteger el ambiente (1). Difícil reto viendo que muchos países poderosos deben dejar a un lado sus intereses para brindar ayuda a países pobres a cambio del bienestar común mundial.

Entre los ocho objetivos del milenio acordados hay uno que reviste particular importancia en nuestra sociedad ya que afecta el núcleo central de esta: la familia y su actor principal la madre gestante, lo cual se menciona en relación al cumplimiento del objetivo quinto "Mejorar la salud materna", que fijó la meta universal de reducir la mortalidad materna en tres cuartas partes en el periodo 1990-2015 (5).

Surge entonces el problema de la multiplicidad de factores y creencias que las personas poseen acerca del concepto de maternidad y más aun de salud materna, en donde el concepto y la forma de manejo de cada materna varían

1,2,3,4 Estudiantes Maestría en Salud Pública. Universidad de Córdoba 
en gran manera de una región a otra creando diversidades de imaginarios sociales acerca de un mismo objetivo; siendo la noción de imaginario social un factor a tener en cuenta para poder alcanzar las metas, por lo aportado al campo de lo social desde una nueva perspectiva para interpretar fenómenos como la producción de subjetividad y la forma en que se invisten afectivamente los cuerpos (6).

Este último elemento desarrollado por Cornelius Castoradis y aplicado a todos los aspectos de la sociedad, podría ser la causa de éxito o fracaso de políticas de salud pública aplicadas a un determinado grupo poblacional.

En concordancia con esta tesis, evidenciamos que cada país, cada región, cada familia y cada persona tienen su propia concepción de lo que para él o ella significa "una maternidad segura" y sobre esta concepción actuarán factores propios que las harán únicas.

Refuerza este concepto Bernal cuando afirma que la salud de la familia y en especial la de la madre gestante es un factor dinámico que está sujeto a variaciones, debido a las influencias de cambio de los factores que la conforman producidos por las vivencias y conflictos familiares relacionados con el tránsito por las etapas del ciclo de vida familiar, por los periodos del ciclo de vida individual de sus integrantes con sus característicos eventos de salud, por la exposición a acontecimientos de la vida cotidiana en la sociedad, y por la propia característica de las relaciones interpersonales familiares (7).

Es claro entonces que esto tendrá implicaciones importantes a tener en cuenta al momento de desarrollar las políticas y estrategias que se deberán implementar por las instituciones sanitarias, para lograr el objetivo trazado de obtener seguridad en nuestras embarazadas.
Pensamos que se debe generar un imaginario social claro permitiendo la capacidad instituyente del colectivo -termino de Castoriadis- (8) y lo más acorde a las condiciones de la región que exprese lo que queremos, procurar como "mejora en la seguridad materna" en los diferentes actores sociales que participan en un embarazo, como base para poder obtener frutos en los loables esfuerzos de la OMS y la ONU.

\section{CONFLICTO DE INTERÉS}

Los autores declaran no tener conflicto de interés.

\section{REFERENCIAS}

1. Rodríguez R, J. Los objetivos del milenio y el desarrollo sostenible. Ánfora [en línea] 2008, 15 (Julio-diciembre): [Fecha de consulta: 11 de abril de 2017] Disponible en:<http://www.redalyc.org/articulo. oa?id=357834257011 > ISSN 0121-6538

2. La CEPAL ante los objetivos de desarrollo del milenio Perfiles Educativos, vol. XXIII, núm. 94, 2001, pp. 91-100 Instituto de Investigaciones sobre la Universidad y la Educación Distrito Federal, México Disponible en: http://www.redalyc.org/ articulo.oa?id=13209406

3. Rodríguez, O, C. Balance De Los Objetivos Del Milenio En Colombia Oasis [en línea] 2010, (Sin mes) : [Fecha de consulta: 11 de abril de 2017] Disponible en:<http://www. redalyc.org/articulo.oa?id=53121459015> ISSN 1657-7558

4. SANAHUJA, J A. Seguridad, desarrollo y lucha contra la pobreza tras el 11-S: los Objetivos del Milenio y la "securitización" de la ayuda". Documentación social, 2005, vol. 136, p. $24-41$ 
5. Ortiz L, E I, Colombia Y El Cumplimiento Del Objetivo De Desarrollo Del Milenio Respecto A La Salud Materna Revista Colombiana de Obstetricia y Ginecología [en línea] 2015, 66 (Abril-Junio): [Fecha de consulta: 11 de abril de 2017] Disponible:

<http://www.redalyc.org/articulo. oa?id=195240441001 > ISSN 00347434.

6. D'Agostino, A M. E., Imaginarios Sociales, Algunas Reflexiones Para Su Indagación Anuario de Investigaciones [en línea] 2014, XXI ( ): [Fecha de consulta: 11 de abril de 2017] Disponible en:<http://www.redalyc. org/articulo.oa?id=369139994011> ISSN 0329-5885.
7. LOURO B, I. Hacia una nueva conceptualización de la salud del grupo familiar y sus factores condicionantes. Rev. cubana Med Gen Integr [online]. 2004, vol.20, n.3 [citado 2017-04-22], pp. 0-0. Disponible en: <http://scielo.sld.cu/ scielo.php?script=sci_arttext\&pid=S 0864

$21252004000300005 \&$ lng=es\&nrm=is o>. ISSN 1561-3038.

8. ERREGUERENA, M. Cornelius Castoriadis: sus conceptos. Revista ANUARIO• UAM-X・ MÉXICO・PP, 2002, p. 39-47. 